\title{
Abordagem laparoscópica e a dispersão de aerossóis durante o manejo do paciente cirúrgico na pandemia por COVID-19
}

\author{
Laparoscopic approach and aerosol dispersion during surgical patient management in the \\ COVID-19 pandemic
}

\begin{abstract}
Abordaje laparoscópico y dispersión de aerosoles durante el manejo del paciente quirúrgico en la pandemia de COVID-19
\end{abstract}

Igor Amorim Amaral ${ }^{1 *}$, Isabela de Souza Freitas Martins ${ }^{1}$, João Paulo Didier Reis ${ }^{1}$, João Pedro Donato Veloso ${ }^{1}$, João Victor Fagundes dos Santos ${ }^{1}$, Nayara Gonçalves Martins ${ }^{1}$, Rafaela Rabelo Gonçalves de Oliveira', Geraldo José de Souza Lima².

\section{RESUMO}

Objetivo: Abordar e revisar o risco de infecção dos profissionais de saúde durante os procedimentos laparoscópicos em pacientes infectados pelo SARS-CoV-2, além de salientar as medidas para minimizar a chance de contaminação. Revisão bibliográfica: Sabe-se que o SARS-CoV-2 apresenta capacidade de infectar diferentes tecidos do corpo humano, como os gastrointestinais. À vista disso, cirurgias abdominais executadas em tecidos infectados pelo vírus podem acarretar a suspensão deste patógeno nos aerossóis liberados pela fumaça cirúrgica ou pelo pneumoperitônio. Dessa forma, o contato da equipe cirúrgica com essa fumaça constitui um fator de risco para a infecção pelo SARS-CoV-2. Todavia, dentre as técnicas disponíveis, a abordagem laparoscópica, apesar de também demonstrar risco de disseminação de partículas virais, possibilita a construção de um ambiente cirúrgico mais seguro, sobretudo se associado às medidas de proteção individual e às técnicas cirúrgicas adequadas. Nesse sentido, é imprescindível a qualificação da equipe, a fim de minimizar a dispersão dos gases potencialmente contaminados. Considerações finais: Por ser um tema recente e controverso, são necessários novos estudos a fim de elucidar a menor dispersão de gases cirúrgicos durante os procedimentos laparoscópicos no paciente com COVID-19.

Palavras-chave: Procedimentos cirúrgicos minimamente invasivos, COVID-19, Aerossóis.

\begin{abstract}
Objective: Address and review the risk of infection by healthcare professionals during laparoscopic procedures in patients infected with SARS-CoV-2, in addition to highlight the measures to minimize the chance of contamination. Bibliographic review: It is known that SARS-CoV-2 has the capacity to infect different tissues of the human body, such as the gastrointestinal ones. In addition, abdominal surgeries performed on tissues infected with the virus can lead to the suspension of this pathogen in aerosols released by surgical smoke or pneumoperitoneum. Therefore, the contact of the surgical team with this smoke constitutes a risk factor for SARS-CoV-2 infection. However, among the available techniques, the laparoscopic approach, despite also showing a risk of dissemination of viral particles, allows the construction of a safer surgical environment, especially if associated with individual protection measures and appropriate surgical techniques. In this sense, it is essential to qualify the team in order to minimize the dispersion of potentially contaminated gases. Final considerations: As this is a recent and controversial topic, further studies are needed in order to elucidate the lower dispersion of surgical gases during laparoscopic procedures in patients with COVID-19.
\end{abstract}

Key words: Minimally invasive surgical procedures, COVID-19, Aerosols.

\footnotetext{
${ }_{1}^{1}$ Pontifícia Universidade Católica de Minas Gerais (PUCMG), Betim - MG. *E-mail: igoramaral67@gmail.com

${ }^{2}$ Hospital Madre Teresa, Belo Horizonte - MG.
} 


\section{RESUMEN}

Objetivo: Abordar y revisar el riesgo de infección por parte de los profesionales de la salud durante los procedimientos laparoscópicos en pacientes infectados con SARS-CoV-2, además de elevar las medidas para minimizar la posibilidad de contaminación. Revisión bibliográfica: Se sabe que el SARS-CoV-2 tiene la capacidad de infectar diferentes tejidos del cuerpo humano, como los gastrointestinales. Ante esto, las cirugías abdominales realizadas en tejidos infectados con el virus pueden llevar a la suspensión de este patógeno en aerosoles liberados por humo quirúrgico o por el neumoperitoneo. Así, el contacto del equipo quirúrgico con este humo constituye un factor de riesgo de infección por SARS-CoV-2. Sin embargo, entre las técnicas disponibles, el abordaje laparoscópico, a pesar de presentar también un riesgo de diseminación de partículas virales, permite la construcción de un entorno quirúrgico más seguro, especialmente si se asocia a medidas de protección individual y técnicas quirúrgicas adecuadas. En este sentido, es fundamental capacitar al equipo para minimizar la dispersión de gases potencialmente contaminados. Consideraciones finales: Dado que este es un tema reciente y controvertido, se necesitan más estudios para dilucidar la menor dispersión de los gases quirúrgicos durante los procedimientos laparoscópicos en pacientes con COVID-19.

Palabras clave: Procedimientos quirúrgicos mínimamente invasivos, COVID-19, Aerosoles.

\section{INTRODUÇÃO}

O vírus SARS-CoV foi isolado em 1937 e reconhecido em 2002 e 2003 por causar uma epidemia de síndrome respiratória aguda grave no ser humano. Dezoito anos após os primeiros casos, um novo CoV, batizado de SARS-CoV-2, tornou-se o responsável pela rápida disseminação mundial da doença COVID-19, que teve o primeiro caso descrito em 31 de dezembro de 2019, em Wuhan, na China. Ao considerar todos os subtipos, sete deles são capazes de infectar humanos de variada intensidade, podendo causar desde infecções assintomáticas ou levemente sintomáticas, até doenças graves e fatalidades (VELAVAN TP e MEYER CG, 2020).

A rápida disseminação do vírus pode ser justificada pela sua capacidade infectocontagiosa que o faz ser transportado por gotículas, por secreções respiratórias e por contato direto com infectados, tendo assim, transmissão direta de humano para humano como um dos principais mecanismos de contágio (BRITO SBP, et al., 2020). Além das gotículas respiratórias, há também a possibilidade de contaminação através de partículas virais presentes em diversos fluidos corporais, como lágrimas, saliva e sêmen. Ademais, o novo coronavírus foi detectado, inclusive, em fezes, sangue total, soro, amostras nasofaríngeas e urina (BOGHDADY ME e EWALDS-KVIST BM, 2020).

Associado a isso, verifica-se que o SARS-CoV-2 pode permanecer viável e infeccioso em aerossóis por até 3 horas após ser eliminado no ambiente, reconhecendo a transmissão indireta como contribuinte para a perpetuação do vírus (DOREMALEN NV, et al., 2020). Tal constatação gera preocupação quanto ao risco aumentado de contaminação de profissionais na realização de procedimentos cirúrgicos (BOGHDADY ME e EWALDS-KVIST BM, 2020). Isso visto que há muito tempo se discute a infecção de profissionais de saúde durante as cirurgias por meio da fumaça cirúrgica, composta em sua maior parte por vapor de água e, em menor parte, por uma suspensão de partículas sólidas, as quais podem incluir os vírus (VEZIANT J, et al., 2020; MINTZ Y, et al., 2020).

Outrossim, com o advento da laparoscopia, uma nova fonte de contaminação do ar por partículas virais foi acrescida, trata-se de aerossóis gerados pelo fluxo de gás do pneumoperitônio (VEZIANT J, et al., 2020; MINTZ Y, et al., 2020). Esse método de exposição, por mais que necessário para realização da cirurgia laparoscópica, pode promover a liberação intencional ou não intencional de $\mathrm{CO}_{2}$ exalando partículas virais e gerando riscos da inalação de fumaça para a equipe cirúrgica (ANTUNES D, et al, 2021).

Esse fato é salientado pelos resultados do estudo realizado por Mintz $Y$ et al. (2020) que demonstra que o risco de contaminação pode ser maior nas laparoscopias, principalmente em situações de vazamento acidental de gás ou controle inadequado da exsuflação, quando comparada à laparotomia. Em contraposto, 
quando se compara à técnica aberta, evidencia-se vantagens referentes à redução da propagação do SARSCoV-2, como a criação de um ambiente cirúrgico fechado, contido e seguro (VEZIANT J, et al., 2020).

À vista disso, debate-se hoje na literatura científica, se a laparoscopia pode ser considerada mais segura para profissionais de saúde no contexto do COVID-19, em comparação à laparotomia (LEEUW RA, et al., 2020). Todavia, vale ressaltar que, ambas as técnicas são consideradas fator de risco para o contágio dos profissionais de risco com o COVID-19. Nesse sentido, torna-se imprescindível a realização de medidas e de protocolos no ambiente cirúrgico, a fim de diminuir a transmissibilidade do vírus e preservar a equipe envolvida na assistência ao paciente (MORRELL ALG, et al., 2020; VEZIANT J, et al., 2020).

Diante disso, este estudo caracteriza-se como uma revisão narrativa de literatura, que objetiva elucidar o risco de transmissão de COVID-19 pela fumaça cirúrgica nos procedimentos cirúrgicos minimamente invasivos, além de enfatizar as medidas que devem ser adotadas para prevenir a contaminação e promover a proteção dos profissionais de saúde.

\section{REVISÃO BIBLIOGRÁFICA}

\section{A fumaça cirúrgica e o pneumoperitônio na transmissão do SARS-CoV-2}

A fumaça cirúrgica pode ser entendida como um subproduto gasoso formado a partir do manuseio dos tecidos de um paciente durante algum procedimento invasivo. Essa nuvem de gás é liberada em decorrência de lesões na membrana da célula-alvo, sendo constituída por $95 \%$ de água e por $5 \%$ de detritos celulares. Dentre essas partículas dispersas, pode-se citar os poluentes inorgânicos $\left(\mathrm{CO}\right.$ e $\left.\mathrm{CO}_{2}\right)$ e orgânicos (hidrocarbonetos), e, sobretudo, os elementos biológicos (células, substâncias mutagênicas, bactérias e fragmentos virais) (VEZIANT J, et al., 2020; VOURTZOUMIS P, et al., 2020).

Nesse sentido, é possível inferir que a fumaça cirúrgica pode exercer a função de reservatório de diferentes microorganismos, tornando-se, portanto, um importante fator de risco biológico para disseminação de infecções. Tal fato é salientado pela constatação da existência de diferentes partículas virais na fumaça cirúrgica, como o papilomavírus humano (HPV) e vírus B da hepatite (HBV) (MOWBRAY NG, et al., 2020). À vista disso, atualmente, a maior evidência de infecção decorrente da interação humana com a fumaça cirúrgica está atrelada ao HPV. Esse contágio é motivado pela disseminação do patógeno devido à inefetividade dos dispositivos de calor que, ao entrarem em contato direto com os tecidos infectados, não desativam os componentes celulares do microorganismo (MOWBRAY NG, et al., 2020; MUN DH, et al., 2020).

Assim, pode-se evidenciar que a literatura científica constata transmissibilidade viral peroperatória pela fumaça cirúrgica, considerando tal situação como fator de risco para a propagação de infecções. Diante disso, sabe-se que o cenário atual é caracterizado como um grande desafio à saúde devido à propagação mundial do SARS-CoV-2, um vírus que apresenta alta transmissibilidade por aerossóis. Por conseguinte, se iniciou o debate sobre a possibilidade de transmissão intra-operatória de COVID-19. Essa hipótese é ainda mais fomentada, sobretudo, por causa das semelhanças estruturais a outros vírus sabidamente propagados por via aerossol. Dentre essas, pode-se citar o tamanho das fitas de RNA que, no caso do coronavírus, é entre 0,06 a $0,14 \mu \mathrm{m}$, enquanto do HBV é de $0,04 \mu \mathrm{m}$ (VEZIANT J, et al., 2020).

À vista disso, pressupõe-se que as partículas virais do SARS-CoV-2 podem se disseminar na fumaça cirúrgica, sobretudo, devido à constatação que $77 \%$ dos elementos existentes neste aerossol apresentam um diâmetro médio de $0,07 \mu \mathrm{m}$. Associado à essa constatação, outro fato que demonstra grande potencial de dispersão desse vírus e o aumento da transmissibilidade é que quaisquer fragmentos menores que $5 \mu \mathrm{m}$ não são filtrados pelas máscaras cirúrgicas, podendo ser inalados pelos profissionais presentes no bloco (VEZIANT J, et al., 2020).

Ademais, sabe-se que o SARS-CoV-2 acomete, sobretudo, o sistema respiratório devido à capacidade da proteína viral Spike (S) de se ligar aos receptores da Enzima Conversora de Angiotensina II (ECA2). Todavia, foi constatado que esse mecanismo patogênico também está atrelado à infecção de outros tecidos que 
dispõem os receptores ECA2, como as células gástricas, duodenais, jejunais, ileais e retais, as células musculares lisas da mucosa e da muscular própria, e as células endoteliais do trato gastrointestinal. Assim, verifica-se que o sistema gastrointestinal pode ser considerado um potencial centro de contaminação para o COVID-19 durante os procedimentos cirúrgicos (BOGHDADY ME e EXALDS-KVIST BM, 2021).

Tal fato é salientado pelo estudo realizado por Bodghday ME e Ewalds-Kvist BM (2021), que evidenciou maior risco de infecção por SARS-CoV-2 nos profissionais de saúde que executam procedimentos abdominais geradores de aerossóis. Dentre essas intervenções, pode-se citar a intubação, a extubação, a inserção de dreno torácico, a broncoscopia, a endoscopia gastrointestinal, a laparoscopia e o uso de dispositivos de energia, como eletrocautério. Vale ressaltar que, esse último instrumento, amplamente utilizado nas cirurgias abertas e laparoscópicas, é apontado como um dos principais contribuintes para formação da fumaça cirúrgica e, por conseguinte, para a propagação viral (BOGHDADY ME e EXALDS-KVIST BM, 2021).

Além disso, outra razão que pode contribuir para a infecção intra-operatória do SARS-CoV-2 é o estabelecimento do pneumoperitônio com o $\mathrm{CO}_{2}$. Essa técnica é utilizada para a consequente expansão da cavidade abdominal nas cirurgias minimamente invasivas, como a laparoscopia, e pode provocar aumento do risco de difusão de aerossóis devido à necessidade de manutenção constante desse gás. Isso ocorre por causa da inserção ou da remoção das válvulas dos trocateres, da introdução e da retirada dos instrumentos, da coleta de amostras e da remoção do pneumoperitônio ao final da cirurgia (BOGHDADY ME e EXALDSKVIST BM, 2021; VIGNESWARAN Y, et al., 2020).

Nesse sentido, evidencia-se, portanto, que o SARS-CoV-2 pode apresentar dois mecanismos de propagação nos centros cirúrgicos: a fumaça cirúrgica e o pneumoperitônio. Por conseguinte, a escolha da técnica cirúrgica adequada para o paciente, seja a minimamente invasiva ou a aberta, é imprescindível para identificação e correção dos riscos de infecção por COVID-19 que os profissionais da saúde estarão sujeitos durante a intervenção (SOMASHEKHAR SP, et al., 2020).

\section{Técnica laparoscópica versus cirurgia aberta na disseminação do SARS-CoV-2}

Ao averiguar a produção de fumaça cirúrgica nos diversos procedimentos cirúrgicos, foi visto que a sua ocorrência estava diretamente atrelada a dois fatores: o tipo de instrumento utilizado e a duração da intervenção. À vista disso, pode-se afirmar que a emissão de aerossóis cirúrgicos sucederá tanto nos procedimentos abertos quanto nos procedimentos minimamente invasivos. Nesse sentido, as recomendações acerca da melhor técnica para prevenir a disseminação da fumaça cirúrgica com decorrente contaminação pelo SARS-CoV-2 é controversa (CHADI SA, et al., 2020).

A princípio, os cirurgiões da cidade de Wuhan, na China, recomendaram laparoscopia altamente selecionada. Entretanto, posteriormente, a laparotomia foi julgada como mais favorável devido à constatação de que a fumaça cirúrgica emitida durante essa técnica apresenta uma concentração de partículas significativamente menores, quando comparadas à laparoscopia. Em contraposto, a Sociedade Endoscópica de Cirurgiões Americanos (SAGES) declarou que a evidência em termos de favorecimento da laparotomia é baixa, sugerindo a abordagem laparoscópica como melhor opção para o manejo do paciente infectado pelo SARS-CoV-2 (RODRUIGUES AZ, et al., 2020).

Já o Colégio Americano de Cirurgiões (CAC) alegou que a escolha da abordagem cirúrgica deve ser direcionada para aquela que permitir maior segurança e qualidade máxima do procedimento, além de um menor tempo de duração. Assim sendo, a experiência do cirurgião, principalmente na técnica laparoscópica, é fundamental para a realização de uma cirurgia com menor produção e disseminação de partículas infectantes por aerossóis (BOGHDADY ME e EXALDS-KVIST BM, 2021).

Partindo disso, explorando-se a abordagem laparoscópica, uma técnica minimamente invasiva, contatase que a perspectiva de formação de um ambiente cirúrgico fechado e, por conseguinte, controlado, pode ocasionar melhor controle da disseminação de aerossóis. Tal fato é sustentado por meio da decisão correta dos pontos de inserção dos trocartes e do manejo adequado dos instrumentos, o que permite o estabelecimento de uma barreira eficiente de contenção entre meio interno e meio externo (CHADI SA, et al., 2020; BOGHDADY ME e EXALDS-KVIST BM, 2021). 
Isso ocorre devido aos princípios de execução dessa técnica que preconizam a instituição, por meio de um insuflador, de um gradiente de pressão entre os dois meios. Por definição, a pressão interna é mantida em torno dos $12 \mathrm{mmHg}$ e dos $15 \mathrm{mmHg}$, à depender do protocolo de cada país (CHADI SA, et al., 2020). À vista disso, foi demonstrado que o uso de pressões mais altas é responsável por maior concentração de partículas na fumaça cirúrgica, além da criação de um jato de alta velocidade pelo trocater nas cirurgias sem uso de filtros. Por conseguinte, acarreta-se em uma dispersão elevada de partículas suspensas nos aerossóis dentro da sala de cirúrgica expondo, dessa forma, todos os profissionais presentes a um maior risco de contaminação (ROBERTSON-MORE C e WU T, 2021).

Ademais, o dispendioso tempo necessário para a execução dos procedimentos minimamente invasivos contribui diretamente para as maiores taxas de aerossolização, além de ocasionar o aumento da contaminação dos instrumentos (RODRUIGUES AZ, et al., 2020; CHADI SA, et al., 2020). Tal fato é salientado pelo estudo realizado por Boghdady ME e Edwalds-Kvist BM (2021) que constatou que a utilização superior a 10 minutos dos dispositivos eletrocirúrgicos aumenta significativamente a chance de transmissão do SARSCoV-2. Agregado a isso, um período cirúrgico mais duradouro compromete a visualização do profissional de saúde por causa do maior número de partículas suspensas da fumaça cirúrgica. Por conseguinte, sucede a necessidade de remoção da luneta para eliminação desse aerossol que ocasiona um aumento do risco de infecção por esse vírus (BOGHDADY ME e EXALDS-KVIST BM, 2021).

A despeito de tais considerações, é pertinente observar que a laparoscopia possui inúmeros benefícios, quando comparada à laparotomia. Dentre esses, pode-se citar a capacidade da primeira técnica de gerar menos tempo de estadia pós-cirúrgica do paciente e, por conseguinte, de ocasionar a preservação da quantidade de leitos nos hospitais, recurso escasso em tempos de pandemia. Outrossim, é consenso que a laparoscopia é um procedimento menos traumático e, por esse motivo, em pacientes infectados pelo SARSCoV-2, uma operação minimamente invasiva comparada a um procedimento aberto pode resultar em diminuição da taxa de mortalidade e em recuperação pós-operatória mais rápida. Por fim, por ser um procedimento com ambiente cirúrgico fechado, delimitado e contido, a cirurgia laparoscópica pode proporcionar a diminuição ou a abolição do contato da equipe com fluidos ou com tecidos contaminados (VIGNESWARAN Y, et al., 2020).

À vista disso, conclui-se que os benefícios propostos pela cirurgia minimamente invasiva são promissores no contexto da pandemia de COVID-19. Todavia, apesar de estar relacionada à menor propagação de partículas virais, quando comparada à técnica aberta, sabe-se que há a necessidade da instituição de protocolos de proteção individual, além de medidas para a evacuação da fumaça cirúrgica (VIGNESWARAN, et al. 2020).

\section{Medidas preventivas na disseminação de partículas virais nos aerossóis}

Diante desse contexto, é evidente que os profissionais da equipe cirúrgica estão sujeitos a um risco aumentado de infecção em procedimentos nos pacientes infectados por COVID-19, seja por cirurgia aberta ou por abordagem minimamente invasiva. Dessa forma, o seguimento de protocolos sobre medidas de controle para a dispersão de aerossóis é imprescindível para a proteção individual e o controle de contaminação (SOMASHEKHAR SP, et al., 2020; MUN D, et al., 2021).

Uma medida inicial a ser tomada é a criação de uma área no centro cirúrgico exclusiva para pacientes com COVID-19. Além do mais, a entrada de objetos não essenciais, como itens pessoais, celulares, canetas e chaves, deve ser proibida. Em relação à anestesia, a técnica regional deve ser utilizada sempre que possível, já que exclui o risco de aerossolização provenientes do procedimento de intubação (SOMASHEKHAR SP, et al., 2020). Ademais, a recuperação anestésica deve ser realizada por uma equipe qualificada, no próprio centro cirúrgico, até a transferência para uma sala isolada (RAMOS RF, et al., 2020).

Sabe-se que cuidados relacionados à proteção individual da equipe cirúrgica minimizam de forma satisfatória o risco de contaminação. Dentre esses, estão o uso de equipamentos de proteção individuais (EPIs) adequados e a redução máxima da circulação de pessoal na sala cirúrgica, sobretudo nos períodos de intubação orotraqueal e de extubação (ABRAS GM, et al., 2021). Ademais, esses procedimentos na via aérea 
do paciente devem ser realizados em sala com pressão negativa, sendo necessário o uso de um filtro viral fixado no tubo endotraqueal e um filtro de intubação para extremidade expiratória do circuito. Junto a isso, a ventilação com pressão positiva deve ser sempre evitada (SOMASHEKHAR SP, et al., 2020).

Em relação ao manejo do pneumoperitônio, devem ser implementados mecanismos de filtragem durante a insuflação e a desinsuflação. À vista disso, esses filtros de $\mathrm{CO}_{2}$ devem ser conectados à porta do trocater, por meio de um tubo padrão, o que permite a evacuação da fumaça cirúrgica e a filtração de possíveis partículas virais. Ademais, deve ser utilizada uma menor pressão intra-abdominal viável, entre 10-12 mmHg, a fim de dificultar a eliminação de partículas (RAMOS RF, et al., 2020).

Além disso, deve-se ter um especial cuidado na introdução e na retirada dos trocateres, assim como na limpeza desses instrumentos. Associado a isso, as válvulas e as borrachas de vedação devem ser rigorosamente verificadas no intuito de evitar vazamento do pneumoperitônio. Outrossim, quando possível, o número de sítios de punção deve ser minimizado e o uso de métodos de vedação em torno das incisões, como o trocater-balão e a cerclagem com sutura, devem ser recomendados. Para mais, a troca de trocartes deve ser minimizada ao máximo, devendo ser retirados após o completo esvaziamento do pneumoperitônio (RAMOS RF, et al., 2020).

Os dispositivos de energia utilizados na manutenção da hemostasia do paciente devem ser evitados. Caso seja necessária, a eletrocauterização deve ser utilizada na potência efetiva mais baixa e no menor tempo possível, devendo ser obrigatoriamente acompanhada de sucção. A fim de minimizar a produção de fumaça cirúrgica, a hemostasia fria deve ser preferida no manejo desses pacientes infectados por COVID-19 (SOMASHEKHAR SP, et al., 2020).

Em relação à indicação dos procedimentos, o tratamento não operatório ou as técnicas minimamente invasivas devem ser sempre considerados (RAMOS RF, et al., 2020). Caso a abordagem cirúrgica seja o único tratamento, aquelas de indicação eletivas devem ser sempre adiadas nos pacientes infectados pelo SARS-CoV-2 (SOMASHEKHAR SP, et al., 2020; MUN D, et al., 2021). Por outro lado, em uma situação de emergência, a decisão de qual melhor abordagem cirúrgica deve ser avaliada individualmente, usando-se como parâmetros de decisão o tempo de pneumoperitônio e a capacidade de recuperação cirúrgica ao trauma da operação.

Além disso, para a escolha da melhor técnica cirúrgica é necessário considerar o preparo da equipe e da unidade no controle da geração e disseminação de aerossóis. Nos centros qualificados para lidar com essas adversidades, a abordagem laparoscópica apresenta menor risco quando comparada à cirurgia aberta. Dessa forma, caberá ao profissional a avaliação adequada do caso e dos riscos expostos a cada procedimento (SOMASHEKHAR SP, et al., 2020; MUN D, et al., 2021).

\section{CONSIDERAÇÕES FINAIS}

Apesar dos indicativos sobre os riscos da dispersão através dos gases do pneumoperitônio, usados na via laparoscópica, ainda faltam evidências determinantes para apontar, exatamente, o risco da transmissão do SARS-CoV-2, para a equipe, durante 0 ato cirúrgico. Entretanto, pequenos esforços podem reduzir a dispersão de gases e, por conseguinte, o risco de contágio, como o uso de equipamentos de proteção individuais e as técnicas que minimizam a transmissão durante 0 ato cirúrgico. Diante disso, este trabalho veio com o intuito de esclarecer sobre a relação da técnica operatória e o risco da transmissão do vírus, inerente a ela, além de apontar medidas que auxiliem na redução do risco.

\section{REFERÊNCIAS}

1. ABRAS GM, et al. $\mathrm{CO}_{2}$ filtration during pneumoperitoneum inflation and deflation in patients undergoing laparoscopy during the COVID-19 pandemic. Revista do Colégio Brasileiro de Cirurgiões, 2021; 48:1-4.

2. ANTUNES D, et al. COVID-19 infection risk by open and laparoscopic surgical smoke: A systematic review of the literature. The Surgeon, 2021; S1479-666X(21)00041-X. 
3. BOGHDADY ME, EWALDS-KVIST BM. Laparoscopic Surgery and the debate on its safety during COVID-19 pandemic: A systematic review of recommendations. The Surgeon, 2021; 19(2): e29-e39.

4. BRITO SBP, et al. Pandemia da COVID-19: o maior desafio do século XXI. Revista Vigilância Sanitária em Debate, 2020; 8(2): 54-63.

5. CHADI SA, et al. Current evidence for minimally invasive surgery during the covid-19 pandemic and risk mitigation strategies. Annals of surgery, 2020; 272(2): 118-124.

6. DOREMALEN NV, et al. Aerosol and Surface Stability of SARS-CoV-2 as Compared with SARS-CoV-1. The New England Journal of Medicine, 2020; 382(16): 1564-1567.

7. ENGLEHARDT RK, et al. Contamination Resulting From Aerosolized Fluid During Laparoscopic Surgery. Journal of the Society of Laparoscopic \& Robotic Surgeons, 2014; 18(3): 1-5.

8. FRANCIS N, et al. SAGES and EAES recommendations for minimally invasive surgery during COVID-19 pandemic. Surgical Endoscopy, 2020; 34(6): 2327-2331.

9. LEEUW RA, et al. COVID-19 and Laparoscopic Surgery: Scoping Review of Current Literature and Local Expertise. JMIR Public Health and Surveillance, 2020; 6(2): 1-22.

10. MINTZ Y, et al. The risk of COVID-19 transmission by laparoscopic smoke may be lower than for laparotomy: a narrative review. Surgical Endoscopy, 2020; 34(8): 3298-3305.

11. MORRELL ALG, et al. Manejo intraoperatório em cirurgia laparoscópica ou robótica para minimizar a dispersão de aerossóis: Adaptações ao contexto da pandemia por COVID-19. Revista do Colégio Brasileiro de Cirurgiões, 2020; 47: 1-7.

12. MOWBRAY NG, et al. Safe management of surgical smoke in the age of COVID-19. British Journal of Surgery, 2020; 107(11): 1406-1413.

13. MUN DH, et al. Intraoperative aerosol viral transmission in minimally invasive surgery: a scoping review and impact on clinical guidelines and practice during the onset of the coronavirus disease 2019 (COVID-19) pandemic. BJU International, 2020; 127(3): 349-360.

14. MUN D, et al. COVID-19 crisis and minimally invasive surgery: a narrative review on intraoperative aerosol viral transmission and their impact on guidelines and clinical practice in Austria. Current Opinion in Urology, 2021; 31(4): 340-345.

15. RAMOS RF, et al. Recomendações do Colégio Brasileiro de Cirurgiões para cirurgia videolaparoscópica durante a pandemia por COVID-19. Revista do Colégio Brasileiro de Cirurgiões, 2020; 47: 1-5.

16. ROBERTSON-MORE C, WU T. A knowledge gap unmasked: viral transmission in surgical smoke: a systematic review. Surgical Endoscopy, 2021; 35: 2428-2339.

17. RODRIGUES AZ, et al. Surgical interventions in coronavirus times: literature review. Brazilian Journal of Development, 2020; 6: 38104-38121.

18. SOMASHEKHAR SP, et al. Adaptations and safety modifications to perform safe minimal access surgery (minimally invasive surgery: laparoscopic and robotic) during the COVID-19 pandemic. SAGE Journals, 2020; 28(1): $123-133$.

19. VELAVAN TP; MEYER CG. The COVID-19 epidemic. Tropical Medicine \& International Health, 2020; 25(3): 278-280.

20. VEZIANT J, et al. Risks of viral contamination in healthcare professionals during laparoscopy in the COVID-19 pandemic. Journal of Visceral Surgery, 2020; 157(3): 59-62.

21. VIGNESWARAN Y, et al. What Is the Appropriate Use of Laparoscopy over Open Procedures in the Current COVID19 Climate?. Journal Of Gastrointestinal Surgery, 2020; 24(7): 1686-1691.

22. VOURTZOUMIS $P$, et al. Operating during COVID-19: Is there a risk of viral transmission from surgical smoke during surgery?. Canadian Journal of Surgery, 2020; 63(3): 299-301. 